\title{
AMOEBA MANAGEMENT SYSTEM TRANSFORMATION IN THE LIGHT OF ORGANISATIONAL CHANGE LITERATURE
}

\author{
Wieslaw Urban \\ Bialystok University of Technology, Faculty of Management, Poland \\ Corresponding author: \\ Wieslaw Urban \\ Bialystok University of Technology \\ Faculty of Management \\ Wiejska 45A, 15-351 Bialystok, Poland \\ phone: (+48) 857469820 \\ e-mail:w.urban@pb.edu.pl
}

Received: 12 October 2016 Accepted: 20 January 2017

\begin{abstract}
The object of this study is the system of amoebas founded originally in Japanese Kyocera. The study aims to identify milestones of the transformation in a company organisational system to the Amoeba Management System (AMS). The study takes a conceptual research approach. It starts from the analysis of available sources on the AMS, identifies the most challenging points of this system, and afterwards, based on organisational change literature, formulates the main steps of transformation towards AMS. The following milestones of AMS implementation emerge from organisational change theories: (1) the preparation for AMS, (2) the change of organisational structure, (3) the design and introduction of a new accounting system, (4) the introduction of inner prices between amoebas, and (5) the transformation of the organisational culture. At the end of the study, the most important issues for future
\end{abstract} research are listed.

KEYWORDs

Amoeba Management System, organisational change, Kyocera.

\section{Introduction}

Employee engagement, bottom-up innovations, and optimal decisions with reference to everyday operations are desired by every manager in every company. There are plenty of tools, systems, and management approaches supporting managers in gaining these advantages. One of them, which is not very popular yet, is the management system founded by Kazuo Inamori in Japanese Kyocera called the Amoeba Management System (AMS). This is a very original system composed of small teams performing in a company similarly to independent small businesses. It causes outstanding workforce engagement and creativeness at the factory floor level.

The author of AMS explained its foundations [1], and other authors have provided fragmentary studies of this system, but ASM has still not been fully clarified and sufficiently studied by scholars. The interesting and important question is how to implement
AMS in ordinary, so-called Western, bureaucratic organisations. The study aims to identify nodal points for the transformation of an organisational system to AMS. The study takes a conceptual research approach. It starts with a review of the fundamentals of AMS and identifies the most challenging shifts which are necessary. Afterwards, based on the organisational change literature, the milestones of AMS transformation are identified and discussed. The study finishes with an indication of the main research challenges for AMS.

\section{Foundations of AMS}

The system of autonomous teams of workers was developed in Japanese Kyocera. This unique system has given the company outstanding growth and development throughout more than the last 50 years. Kyocera, a globally operating company, has brought profit each year during the last 50 years [2]. In the 
last 20 years, the ratio of net income to net sales has constantly been at levels between $5-10 \%$, except for the years of the global crisis, when the ratio fell to $3 \%$ [3]. High flexibility and efficiency allowed the company to keep positive financial results during the crisis. Scholars studying the organisational system of Kyocera suggest that it may lead to extraordinary market expansiveness, dynamism in productivity increase, and superior increase in competitiveness [4].

The Kyocera system of amoebas is composed of small, independently working, highly entrepreneurial units called amoebas. They were named amoebas because they are small, simple, very flexible, selforganised and self-developing in terms of entrepreneurial changes. Amoebas are so independent that they look like separate businesses within a company. A company organised according to the AMS consists of numerous small units (amoebas), and each unit is focused on the value created within it, and as Inamori says, each unit works under one fundamental idea: 'maximise revenues — minimise expenses' [1].

A single amoeba might be made up of 3 to 50 employees [5]. An amoeba has a wide range of competence and authority; it sets and executes its own plans and operates on its own settlement. A company working according to the AMS becomes a chain of cooperating enterprises because all its functions are organised according to amoeba logic. Some amoebas serve in the administration, some in sales, others in production, etc. In production, each amoeba handles particular stages of the production process.

An amoeba is similar to a small business company. The amoeba's leader acts like a businessman who is responsible for inner coordination and coordination with other amoebas. The whole coordination is organised very efficiently. There are meetings at three levels of the company: (1) divisional managers and sectional managers, (2) sectional managers meet with amoeba leaders, and, finally, (3) amoeba meetings - the leader with the amoeba's workers [6]. These coordination meetings are carried out every day. They are very short and focused on concrete things. The time devoted to them daily is no longer than 10 minutes in the case of a machine operator [6] and 60 minutes in the case of a senior manager [2].

The idea of highly autonomous working teams can turn into reality only when these teams are operating in fully realistic economic conditions so that each amoeba is equipped in a real and timely finance calculation. For this, amoebas need realistic inner transfer prices. The transfer prices are determined through a process of bargaining and negotiations so that they are very consistent with market conditions and are comparable to market prices [3]. Amoebas complete processes and subcontract them, and generally cooperate among themselves on the basis of the intracompany market, which is an equivalent of the real market [7]. Inner prices determine the amoeba's profit, but while setting the selling prices, the amoeba cannot consider only its own profit, but also the profitability of the whole company [1].

For the delivery of financial information to amoebas, a completely new system of accounting information is required. At Kyocera, this system performs diagnostic and control functions [6]. An amoeba's results are planned monthly and yearly based on the scheme of a standard financial report. Monthly results are reported in meetings, where all the figures are discussed and compared to monthly targets and annual targets. The reliability of the whole organisational system is based on the fact that a great deal of attention is devoted to ensuring that this accounting information accurately reflects the internal and external transactions of each amoeba [2].

The AMS can operate effectively thanks to very clear principles and values which are deeply inbuilt into the company's organisational culture. All the principles are called the company's philosophy. The philosophy consists of a corporate motto, a management rationale, principles and philosophy keywords [4]. The Kyocera's philosophy forms a strongly ethical set of general tips for organisational behaviours and their personal attitudes. The philosophy is provided in a printed publication called The Kyocera Philosophy Pocketbook. This publication is given to each employee on their first day of work for the company [8]. The philosophy book is actually used by employees. For example, during morning meetings employees read pieces of this book [6]. A great deal of effort is made to ensure that all elements of the philosophy represent real living guidance for work and the social cement of the company.

\section{Most challenging issues of AMS}

The Amoeba System has been developed over the years, and without a doubt, it is very challenging to introduce it into a traditionally organised bureaucratic organisation. Organising a small team system within the whole company is not particularly difficult. But the most challenging aspect seems to be to give the small teams far-reaching autonomy and transfer to them full responsibility for their work. This requires a diametric change in thinking and in the management style of managers and workforce treatment. The traditional management styles should be discarded, and managers must move to the positions of advisors, coordinators, and facilitators. 
As Adler and Hiromoto state, a particular responsibility lies with amoeba leaders to promote their people empowerment [2] but managers, including those in higher positions, have a lot to do in this matter.

Another challenging issue is an accounting system suitable for AMS needs. Traditional accounting systems, firstly fulfil the needs of tax offices. Inamori himself is highly critical of traditional accounting systems. He states that they operate on global figures and report only historical data, and such figures are useless for managing amoebas [1]. The AMS needs a completely different accounting system which provides reliable information about the total expenses of an amoeba, including all costs tied to facilities engaged and operations done by an amoeba.

To understand the real added value produced by an amoeba, besides reliable information on expenditure, prices are necessary. These should be real prices, which means they should be closely related to real market conditions. For pricing the products of amoebas, the inner market is necessary, as well as the information about the prices on the external market. The value added by an amoeba is called the amoeba profit - it is calculated as the balance remaining after subtracting the total expenses, other than labour costs, from the volume of production sold to other amoebas, multiplied by the price. The typical indicators calculated for amoebas are the 'workers' profit' and 'hourly workers' profit'. Each of them needs reliable inner transfer prices.

Amoebas, being very autonomous and selfgoverning units, urgently need clear rules to work efficiently and be coordinated effectively for a company's success. A very strong organisational philosophy serves amoebas as guideposts in everyday operations and helps in management decisions. It is highly probable that the original philosophy should be noticeably adjusted when it is incorporated into the cultural conditions of different countries, particularly European ones. There is a need to have deeply rooted organisational behaviour principles which will be strongly respected by all amoeba workers, as well as all managers. As a starting point for developing the company's philosophy, the statement 'do what is right as a human being' can be taken, which best summarises the philosophy of Kyocera introduced by Inamori [2].

\section{Framework of the organisational change theory}

Organisational development is an absolutely fundamental issue for any business organisation operating in a competitive market. The earliest concept of organisational change is proposed by Lewin [9]; it thrives on three steps: (1) unfreeze the current state of the organisation, (2) implementation of desired changes in the organisation, and (3) refreeze the implemented changes. The model was proposed in the 1940s, and from today's perspective, some authors consider it as more congruent to individuals' development and conflict solving [10].

From the early models, like that proposed by Lewin, the management theory has been enriched by many strategies, approaches and methods of organisational change. Al-Haddad and Kotnour [11] provide a comprehensive review of organisational change theory. They define change methods as the actions carried out by managers to deal with change, and group them into two categories: systematic change methods and change management methods. The systematic change approach is represented by eleven specific methods, e.g. Business Process Reengineering, TQM and Six Sigma.

To managers, the systematic change methods offer particular kinds of steps leading to particular effects within the organisation, and they are very systematic, cyclical and integrative, involving higher scales of organisational change [11]. The strengths of these methods are the fact that most of these methods have frequently confirmed their effectiveness practically, and they have brought numerous benefits to companies. Most of these methods are strongly tied to so-called management philosophies.

The change management methods, according to Al-Haddad and Kotnour [11], are broader and more conceptual in comparison to systematic change methods. They provide steps and procedures for any kind of organisational change, including culture, social relations, technology and strategy changes. One method from this group is a procedure proposed by Luecke [12], which is a sequence of steps whereby special attention is devoted to the preparation stage, including forming a coalition and creating and communicating a vision. Authors [11] qualify six more methods to this group, including three steps, one by Lewin [9] mentioned above. Both groups of methodologies provide very valuable tips for how to deal with organisational change, which can generally be utilised in different organisational development projects.

\section{Milestones of AMS implementation driven from the organisational change theory}

Lewin's organisational change theory [9] suggests unfreezing the organisation for forthcoming changes 
by strengthening the group behaviours for change and enhancing the leader's pressure for change. Also, others see the necessity of appropriate preparations before substantial organisational changes occur. Kanter et al. [13], in the organisational change methodology, propose starting with an analysis of the organisation in terms of the need for change, and creating a vision of the organisation how it may look after the changes. Kotter [14] sees the necessity of having a vision and strategy while approaching organisational change, and eventually communicating this vision within the organisation. The literature suggests that the substantial structural organisational changes absolutely require a well-conducted preparatory phase, and, therefore, the first phase of AMS implementation should be:

\section{\#1. Comprehensive preparation for AMS implementation in the organisation}

First of all, the managers should clearly answer the question 'why?'. Why is the AMS going to be introduced into the organisation, what kind of advantages would a company gain, and, necessarily, what are the consequences for employees? The answers to these questions are the elements of a wide vision of the AMS in a particular company. This vision should be expanded and strengthened throughout the organisation. Training for managers and the workforce on AMS can be an important component of the preparation stage, and at the same time, a means of spreading the new organisational vision. Many literature sources mention the crucial role of change agents or change leaders $[12,15]$. During the preparation, it is necessary to establish and properly train leaders for the time of changes. Technically, this is also a time for deliberation on how to segment organisational processes for forming small teams amoebas. The Value Stream Mapping approach [16] is particularly helpful for this purpose. Along with the preparation stage, the beginning of organisational culture transformation to approach features typical for amoebas must be inculcated. An interesting hint is given by Judson [17], who states that before changing the status quo in an organisation the wide acceptance of new behaviours is necessary, and this should serve as a trigger for the next steps.

After the preparation activities, including the development of a change vision and leadership for changes, Luecke [12] suggests starting changes at the peripheries and letting it spread to the rest of the company. According to the Business Process Management approach, which is a very radical methodology of organisational change, the first cycle of reengineering should be executed on a chosen process [18].
Transforming an organisation towards the system of amoebas also requires very fundamental changes, so it is considered necessary to execute changes gradually, considering the specificity and size of a company. Frist of all, changes in the organisational structure are required.

\section{\#2. The change of the organisational structure}

AMS is composed of a collection of small teams operating almost like small companies, and each amoeba creates a particular part of the value added within a company. Before full responsibility is given to amoebas, they should be organised according to particular processes sections. Forming teams according to the AMS logic should presumably be the first act of real change on the route to the new management model. It takes some time for people to adjust to the range of processes performed. From this time, amoebas could be progressively empowered. Along with the organisational structure change, the Business Systems Administration Department, which according to Inamori [1] is responsible for the development of ASM and for information delivery for teams, should be established.

According to the literature, one of the middle steps of organisational changing paths is empowering others to act on the vision [28]. When the teams (amoebas) are formally established, they should gradually achieve more and more independence and responsibility. McGuire and Hutchings underline the detrimental nature of uncertainty, which undermines confidence and support for organisational leaders as facilitators of change [19]. They suggest careful assessment of the impact of change on the existing norms, values, and the quality of working life of employees. The new structure and increasing responsibility may lead to anxiety and fear among employees. The change leaders should promptly react to unbalanced workloads, and where employees feel that their privileges have been removed. Various forms of compensation should be adopted to deal with this. When the system of teams is established and stabilised, a company can start providing individualised financial data to amoebas.

\section{\#3. The design and introduction of an accounting system coherent with the amoeba structure}

AMS needs completely different financial reporting compared to traditional accounting systems. Accounting systems in companies operate in the environment of computer programs, and the systems and IT tools are standardised, which means that on- 
ly limited options are allowed. The amoeba approach needs to go beyond these limitations, and designing and making real a working reporting system providing reliable and timely data for each amoeba is absolutely necessary. Inamori states that the team's creativity has sources in real time financial information, particularly, hourly efficiency reports [1]. In designing a new accounting system, the experiences of Activity-Based Costing can be particularly useful. Unlike the traditional approach, this approach assumes that costs vary not only with the production volume but also with some other measures of activity [20]. When amoebas are equipped with appropriate financial data, it is possible to make the crucial step of making amoebas into small businesses.

\section{\#4. The introduction of inner prices between teams}

Amoebas starting working on their own settlement seems to be an essence of Inamori's management system [1]. It allows full rationalisation of operations at the work floor level and optimisation of operational decisions. But it is highly challenging to introduce negotiation routines between amoebas, and continuous comparison with external market conditions. In comparison to market conditions benchmarking methodology, meant as a learning and evaluation process [21], it would be particularly supportive. The transformation to inner transfer prices between amoebas is a radical change, and, therefore, it may cause fear among employees. Moran and Brightman [22] suppose that people are afraid because they feel incapable of fulfilling the expected new conditions. Teams need to test the change in a safe environment where they can ask questions without fear of consequences and evaluate and manage the costs and benefits of the change in an objective manner [22].

\section{\#5. Transformation of the organisational culture to the AMS values and principles}

According to the organisational change literature, the execution of changes should be deeply ingrained in the organisational culture [12]. The issue of organisational culture is particularly important because originally in Kyocera exists a very distinct culture which is firmly tied to a long list of principles [23]. At the same time, it should be underlined that the direct duplication of organisational culture is very difficult or even impossible. Without a doubt, a company should respect its local culture. According to
Smith, the length of cultural changes ranges from four to ten years. From his research, the view emerges that the success of culture change is more probable when, among other things, change is rewarded, there is visible support from a change sponsor, and the changes are tracked and publicised [24]. The organisational culture of AMS is strongly ethically focused, so that corporate ethical codes and corporate ethics programmes, which are considered critical in the development of a culture of ethics [25], can serve as important support in the culture transformation to AMS.

\section{Discussion}

AMS is a management system in many characteristics diametrically different from systems existing in ordinary bureaucratic organisations [26]. Its introduction dramatically shifts the sense of typical roles in the organisation, workforce approach to work, structure and communication, as well as management styles. Its introduction should be thoughtfully harmonised, and much of the effort should be devoted to the elimination of tension and resistance to change which inevitably appear. In Table 1, the mutual spread over time of the key change steps identified in the previous paragraph is presented. Along with the preparation step, the fifth step devoted to organisational culture changes, which in fact is the longest one in all the transformation process, should be launched. While the reconstruction of the organisational structure is started (\#2 milestone), a company should start working on the design and introduction of a new accounting system (\#3 milestone). To be able to employ inner prices between amoebas (\#4 milestone) a reliable accounting information system is apparently needed.

For a company planning such significant changes as AMS implementation, it is particularly important to clearly understand the reasons behind such decision. The answer to the question 'Why?' should resound loudly and clearly to every corner of the company. It must be noted that behind all popular management concepts, stand strong hopes of extraordinary advantages. Lean Management is tempting because of the extraordinary results Toyota has experienced [27]; TQM promises outstanding product quality overcoming competitor's ones [28, 29]; BPM points to fast and large effectiveness growth [30]. The scarce literature referring to AMS, in fact, does not talk much about the fruits of the system. 
Table 1

Sequence of AMS transformation milestones.

\begin{tabular}{l|l}
\hline \multicolumn{1}{c|}{ Transformation milestones } & Time \\
\cline { 2 - 2 } $\begin{array}{l}\text { \#1. Comprehensive preparation for AMS implementation in the } \\
\text { organisation }\end{array}$ & \\
\hline \#2. The change of the organisational structure & \\
\hline \#3. The design and introduction of the accounting system coherent & \\
with the amoeba structure & \\
\hline \#4. The introduction of inner prices between teams & \\
\hline \#5. Transformation of the organisational culture to AMS values and \\
principles
\end{tabular}

According to Gallup's Q12 research, a mere 30\% of the US workforce is engaged in their work, another $52 \%$ of employees are not engaged, and another $18 \%$ are actively disengaged [31]. Many studies demonstrate interdependencies between workforce engagement and a variety of organisational and business performance indicators, namely the level of operating margin and net profit margin [32], customer ratings, productivity, theft, absenteeism, product quality [31] and innovativeness [33]. AMS is probably one of the most effective answers referring to the biggest sore point of modern organisations - shortcomings in the workforce engagement. The AMS approach seems to have inbuilt some mechanisms important for workforce engagement: (1) there is close cooperation within small groups, which facilitates engagement raised from a personal identification and responsibility for the work undertaken, (2) engagement is stimulated by clear financial figures, which reflect the real performance of small teams, (3) amoebas' work is continuously confronted with the real market, and employees are fully aware of what value they produce. This forces identification with what they are doing; (4) another issue affecting engagement is a strong organisational culture authentically rooted and based on higher transcendent values closely tied to devotion and a sense of mission.

McGuire and Hutchings highlight the primary meaning of individuals' motivation, change of the existing quality of the working life of employees, and change of received benefits as particularly important in the organisational changes process [19]. The AMS implementation in all of its stages, starting from preparation and to the culture transformation and the accompanying changes of principles, should carefully consider these issues. Negligence in this respect could lead to the failure of the entire project. As Emiliani warns those implementing the Lean Management approach: not keeping real respect for peo- ple eventually leads to fake Lean in a company [34]. Machiavelli argues that while the struggle for success is operationalised in terms of money, it should be expressed in terms of the soul [19]. This implies the continuous proclamation of the change vision during the whole changing process as indispensable.

\section{Conclusions}

This conceptual study shows that AMS is a very advantageous and promising system. But on the other hand, AMS is difficult to introduce in a company because it requires profound changes in many areas of the company. The most challenging issues refer to changes in the organisational structure, new management styles, attitudes towards work and values inbuilt in the organisational culture, and a new financial reporting system. But supposedly the effects of AMS introduction are beneficial enough to take on these challenges.

Organisational change theory proposes many approaches and concepts, including great amounts of knowledge contributed by standardised management methodologies, such as TQM and BPM. All of them allow the identification of five milestones of AMS transformation, where the starting point is an ordinary bureaucratic organisation and the final destination is an organisation operating according to the AMS approach. These milestones take a pretty long time and need a great commitment from the top management. This transformation path is important because this issue of transformation from a traditional organisation is not mentioned in the literature.

But still, there are plenty of interesting questions for further research on AMS. The first one is about comprehensive studies on the effects brought by AMS in companies. However, the number of AMS implementations is still limited. Other interesting issues are as follow: the transmission of AMS organisational 
culture to other countries and the necessity of adjustments, internal bargaining techniques between amoebas, new accounting systems for different countries coherent with domestic accounting standards, and how to lead an individual from a command and control working system to full responsibility for his/her work.

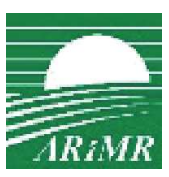

7th International Conference on Engineering, Project, and Production Management (EPPM2016) was co-organised by the Agency for Restructuring and Modernisation of Agriculture (Poland).

\section{References}

[1] Inamori K., Amoeba Management. The Dynamic Management System for Rapid Market Response, CRC Press, Boca Raton, 2013.

[2] Adler R.W., Hiromoto T., Amoeba Management: Lessons From Japan's Kyocera, MIT Sloan Management Review, 54, 1 83-89, 2012.

[3] Kyocera Corp., Consolidated Financial Data, $1997-$ 2016.

[4] Takeda H., Boyns T., Management, accounting and philosophy, Accounting, Auditing \& Accountability Journal, 27, 2, 317-356, 2014.

[5] Hamada K., Monden Y., Profit management at Kyocera Corporation: the amoeba system in: Monden Y., Sakurai M. [Eds.], Japanese Management Accounting - A World Class Approach to Profit Management, Productivity Press, Cambridge, 197-210, 1989.

[6] Sawabe S., Value-driven responsibility accounting: dynamic tensions generated by competing values embedded in the management control system, Kyoto University, Graduate School of Economics, Discussion Paper no. E-14-020 2015.

[7] Blahová M., Effective Strategic Action: Creating Dynamic Performance Framework Based on the Utilization of Synergy Effects of Bata, Japanese and Amoeba Management Systems, Doctoral thesis, Tomas Bata University in Zlin, Faculty of Management, 2013.

[8] Sawabe N., Kazusa Y., Ushio S., Dialectic Dynamics of Management Accounting and Management Philosophy, NZMA, 2008.

[9] Lewin K., Field theory in social science, Harper \& Row, New York, 1947.

[10] Burnes B., Kurt Lewin and the planned approach to change: a re-appraisal, Journal of Management Studies, 41, 6, 977-1002, 2004.
[11] Al-Haddad S., Kotnour T., Integrating the organizational change literature: a model for successful change, Journal of Organizational Change Management, 28, 2, 234-262, 2015.

[12] Luecke R., Harvard Business Essentials. Managing Change and Transition, Harvard Business School Press, Boston, 2003.

[13] Kanter R.M., Stein B., Jick T., The Challenge of Organizational Change: How Companies Experience it and Leaders Guide it, Maxwell Macmillan, New York, 1992.

[14] Kotter J.P., Leading Change, Harvard Business School Press, Boston, 1996.

[15] Moran J.W., Brightman B.K., Leading organizational change, Journal of Workplace Learning, 12, $2,66-74,2000$.

[16] Rother M., Shook J., Learning to See: Value Stream Mapping to Add Value and Eliminate MUDA, Lean Enterprise Institute, Cambridge, 1999.

[17] Judson A.S., Changing Behavior in Organizations: Minimizing Resistance to Change, Blackwell, Oxford, 1991.

[18] Sikdar A., Payyazhi J., A process model of managing organizational change during business process redesign, Business Process Management Journal, 20 6, 971-998, 2014.

[19] McGuire D., Hutchings K., A Machiavellian analysis of organisational change, Journal of Organizational Change Management, 19, 2, 192-209, 2006.

[20] Lere J.C., Activity-based costing: a powerful tool for pricing, Journal of Business \& Industrial Marketing, $15,1,23-33,2000$.

[21] Saunders M., Mann R., Smith R., Benchmarking strategy deployment practices, Benchmarking: An International Journal, 14, 5, 609-623, 2007.

[22] Moran J.W., Brightman B.K., Leading organizational change, Journal of Workplace Learning, 12, 2, 66-74, 2000.

[23] Global Kyocera, available: http://global.kyocera.com, last accessed 21st October 2016 .

[24] Smith M.E., Changing an organisation's culture: correlates of success and failure, Leadership \& Organization Development Journal, 24, 5, 249-261, 2003.

[25] Singh J.B., Changes in the contents of corporate codes of ethics: an institutional interpretation, European Business Review, 27, 4, 369-388, 2015.

[26] Zeleny M., Amoeba: The New Generation of SelfManaging Human Systems, Human Systems Management, 9, 2, 57-59, 1990. 
[27] Liker J.K., The Toyota Way: 14 Management Principles from the World's Greates Manufacturer, McGraw-Hill, New York, 2004.

[28] Goetsch D.L., Davis S., Quality Management for Organizational Excellence: Introduction to Total Quality, 8th Edition, Pearson, London, 2015.

[29] Ejdys J., Matuszak-Flejszman A., Szymanski M., Ustinovicius L., Shevchenko G. Lulewicz-Sas A., Crucial factors for Improving the ISO14001 Environmental Management System, Journal of Business Economics and Management, 17, 1, 52-73, 2016.
[30] Hammer M., Champy J., Reengineering the Corporation, Harper Business, New York, 1993.

[31] Gallup, State of the American workplace, 2013.

[32] Towers Perrin-ISR, Engaged employees drive the bottom line, 2007.

[33] MacLeod D., Clarke N., Engaging for success: enhancing performance through employee engagement, UK Government, The Department for Business, Innovation \& Skills, 2009.

[34] Emiliani B., Real Lean: Understanding the Lean Management System, Vol. 1, The Center for Lean Business Management, Wethersfield, 2007. 